Disponível em

http://www.anpad.org.br/rac

RAC, Rio de Janeiro, v. 18, n. 5, art. 2, pp. 577-597, Set./Out. 2014

http://dx.doi.org/10.1590/1982-7849rac20141154

$($ (c) EY-No

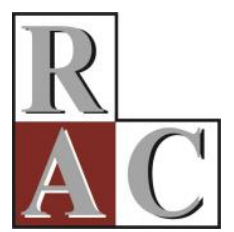

\title{
Determinantes Nacionais e Setoriais da Estrutura de Capital na América Latina
}

\author{
National and Industry Determinants of Capital Structure in Latin America
}

Henrique Castro Martins

E-mail: hcm@ufrgs.br

Universidade Federal do Rio Grande do Sul - PPGA/EA/UFRGS Rua Washington Luís, 855, Sala 321, 90010-460, Porto Alegre, RS, Brasil.

Paulo Renato Soares Terra

E-mail: prsterra@ea.ufrgs.br

Universidade Federal do Rio Grande do Sul - PPGA/EA/UFRGS Rua Washington Luís, 855, Sala 321, 90010-460, Porto Alegre, RS, Brasil.

Artigo recebido em 30.10.2012. Última versão recebida em 09.06.2014. Aprovado em 11.06.2014. 


\title{
Resumo
}

Este estudo identificou o papel do ambiente nacional (Macroeconomia, Desenvolvimento Financeiro e Qualidade Institucional) e das características dos setores de atividade (Munificência, Dinamismo, Concentração, Ciclo de Vida, Dispersão da Eficiência Tecnológica, Dispersão da Qualidade dos Produtos, Poder de Barganha dos Clientes e Poder de Barganha dos Fornecedores) sobre o endividamento de 612 companhias abertas de sete países da América Latina (Argentina, Brasil, Chile, Colômbia, México, Peru e Venezuela). Para fins de comparação, estende-se a análise, também, a 847 companhias dos Estados Unidos. O período estudado é o de 1996-2009 e, para a análise, utiliza-se o Modelo Linear Hierárquico, que permite controlar os efeitos de acordo com o nível das variáveis (país, setor, tempo e firma). Os resultados sugerem que o Desenvolvimento Financeiro facilita o acesso a recursos de terceiros e que a Qualidade Institucional é negativamente relacionada com a Alavancagem das empresas. Encontraram-se, também, evidências de que a Qualidade Institucional pode promover o desenvolvimento assimétrico entre o mercado acionário e o de crédito.

Palavras-chave: estrutura de capital; desenvolvimento financeiro; qualidade institucional; América Latina; modelo linear hierárquico.

\begin{abstract}
This study identified the role of the national environment (the Macroeconomy, Financial Development and Institutional Quality) and industry characteristics (Munificence, Dynamism, Concentration, Life Cycle, Technological Efficiency Dispersion, Product Quality Dispersion, Customer Bargaining Power and Supplier Bargaining Power) on debt of 612 listed companies from 7 Latin American countries (Argentina, Brazil, Chile, Colombia, Mexico, Peru and Venezuela). For comparison purposes, the analysis is also extended to 847 U.S. companies. The period of study is 1996-2009 and the analysis employed a Hierarchical Linear Model, which controls the effects according to the level of the variables (country, industry, time and firm). The results suggest that Financial Development eases access to external funds and Institutional Quality is negatively related to firm Leverage. The research also finds evidence that institutional quality can promote asymmetrical development between stock markets and credit markets.
\end{abstract}

Key words: capital structure, financial development, institutional quality; Latin America; hierarchical linear model. 


\section{Introdução}

O artigo seminal de Modigliani e Miller (1958), valendo-se de uma série de premissas restritivas, resumidamente, indicou que o valor de uma firma deveria ser independente de sua estrutura de capital. Tal trabalho gerou uma série de testes empíricos que, na maioria dos casos, não confirmou a hipótese inicial devido às premissas restritivas impostas pelos autores. Em virtude disso, um conjunto de hipóteses teóricas alternativas passou a sugerir explicações acerca do tema. As mais conhecidas são: (a) hipótese do tradeoff estático (Miller, 1977; Miller \& Modigliani, 1961); (b) pecking order (Myers, 1984; Myers \& Maljuf, 1984); e (c) teoria da agência (Jensen, 1986; Jensen \& Meckling, 1976; Myers, 1977). No entanto nenhuma hipótese conseguiu explicar, de forma isolada, as escolhas de estrutura de capital.

O objetivo aqui é investigar quais são os determinantes relevantes para a Alavancagem Corporativa na América Latina. Para tanto, foi utilizado o Modelo Linear Hierárquico como método estatístico. Trabalhos empíricos prévios visam às variáveis em nível de firma e dão pouca atenção aos possíveis fatores setoriais. Para avaliar a importância das características dos setores, portanto, seguiu-se Copat e Terra (2009), Copat (2009) e Kayo e Kimura (2011) e deu-se maior atenção às variações setoriais a partir de diversas variáveis contínuas. Além disso, Kirch e Terra (2012) constataram que a Qualidade das Instituições domina o Desenvolvimento Financeiro, enquanto determinantes da estrutura de capital. O presente estudo revisita esse problema sob uma nova ótica e encontra resultados distintos. Em paralelo, embora Demirgüç-Kunt e Maksimovic (1999) e Giannetti (2003) tenham sugerido que a Qualidade Institucional possibilita o aumento da Alavancagem, Li, Yue e Zhao (2009) encontraram, empiricamente, relação negativa entre essas variáveis. Sua explicação sugere que o desenvolvimento institucional impacta, diferentemente, os mercados de ações e de dívidas. Destaca-se que se deu especial atenção a essas variáveis e encontraram-se resultados que corroboram os estudos de Li et al. (2009).

Os resultados obtidos indicam que as variáveis em nível de firma Tangibilidade e Tamanho (relações positivas) suportam a hipótese do tradeoff estático, ao passo que Liquidez (relação negativa) e Lucratividade (relação negativa) apresentaram efeitos conforme os previstos pela pecking order. Por sua vez, a medida de Oportunidades de Crescimento (relação negativa) está de acordo com a Teoria da Agência. Entre as variáveis setoriais, Munificência (disponibilidade dos recursos no setor) se relaciona negativamente com o endividamento, o que corrobora os achados de Kayo e Kimura (2011). Já Poder de Barganha dos Clientes e Poder de Barganha dos Fornecedores apresentaram relação positiva e significativa com Alavancagem - Copat (2009) encontrou apenas fracos indícios de tal relação em empresas americanas. Também há sinais de que a Taxa de Inflação (relação negativa) e a Taxa Real de Juros (relação positiva) são importantes determinantes da Alavancagem corporativa.

O fator relativo à Qualidade das Instituições se mostrou negativamente relacionado com o nível de endividamento, porém o Desenvolvimento Financeiro assinalou relação positiva. Quando se incluem os Estados Unidos na amostra (a partir daqui referida como amostra AL/EUA), a relação entre a Qualidade Institucional permanece negativa, no entanto o Desenvolvimento Financeiro passa a ter relação, igualmente, negativa. Tais resultados contrastam com Kirch e Terra (2012) e sugerem que não há relação de dominância desse grupo de variáveis. Além disso, encontraram-se evidências de que a Qualidade Institucional favorece o desenvolvimento do mercado acionário.

O restante do estudo foi construído da seguinte forma: na próxima seção, encontram-se os determinantes da Alavancagem estudados e as hipóteses teóricas relacionadas. A seguir, descrevem-se a amostra e o método utilizados. Na seção seguinte, apresentam-se resultados. Finalmente, trazem-se as considerações finais. 


\section{Determinantes da Alavancagem Corporativa}

A análise dos trabalhos empíricos prévios sugere que há cinco grupos de determinantes da Alavancagem Corporativa: (a) Variáveis da Firma, (b) Variáveis do Setor, (c) Variáveis Macroeconômicas, (d) Variáveis de Desenvolvimento Financeiro e (e) Variáveis de Qualidade das Instituições. Essa seção destina-se a apresentar os trabalhos que descrevem tais variáveis e relacioná-las com as hipóteses teóricas subjacentes

\section{Variáveis específicas da firma}

Segundo Baxter (1967), há um risco associado ao aumento da Alavancagem de uma empresa pelo aumento do risco de falência. A depender do nível de Alavancagem, o risco de falência pode ser maior que o benefício fiscal da dívida (Kraus \& Litzenberger, 1973). Desse modo, as empresas têm um nível ótimo de dívida que otimiza a relação benefício fiscal da firma e custo de falência (tal hipótese ficou conhecida como tradeoff estático). Segundo a teoria do tradeoff estático, um maior nível de ativos tangíveis representa menor risco aos credores, de modo que a empresa é capaz de tomar proporções maiores de dívida; analogamente, empresas maiores apresentam menor probabilidade de recorrer à falência, de forma que podem assumir maiores proporções de dívida (Titman \& Wessels, 1988). A mesma relação positiva com o endividamento é indicada pela pecking order, em razão das empresas mais tangíveis e aquelas maiores potencialmente apresentarem menor assimetria informacional. Por sua vez, Fan, Titman e Twite (2012) argumentam por uma relação positiva entre a Carga Fiscal e Alavancagem em decorrência do aumento do benefício fiscal do endividamento.

Para Fama e French (2002), os custos de falência têm relação negativa com a Lucratividade. Consequentemente, para a teoria do tradeoff estático, empresas mais lucrativas podem aumentar seu endividamento a fim de aumentar o benefício fiscal pelo uso da dívida. Porém, para a teoria do pecking order, essas empresas emitem menos dívida para evitar a assimetria de informação envolvida no lançamento de dívidas (Myers, 1984). Similarmente, para a teoria da pecking order, quanto maior o nível de Liquidez da firma, menor a necessidade de se assumir novas dívidas (Myers \& Maljuf, 1984).

Quanto ao nível de Oportunidades de Crescimento, as hipóteses teóricas sugerem relações contrastantes. Entretanto, para o tradeoff estático e para a teoria da agência, Oportunidades de Crescimento têm pouco valor caso a empresa entre em processo de falência e não são boas garantias reais. Dessa forma, sugere-se relação negativa com endividamento. Mas, segundo a pecking order, empresas de crescimento potencialmente não geram internamente todo o capital necessário aos investimentos, o que provoca necessidade maior de endividamento.

\section{Variáveis específicas dos setores}

Poucos trabalhos incluem variáveis setoriais. Fan et al. (2012) observaram que a inclusão de variáveis binárias (dummies) setoriais aumenta (ainda que marginalmente) o $\mathrm{R}^{2}$ de regressões cuja variável dependente é Alavancagem. Kayo e Kimura (2011) encontraram que aproximadamente 12\% das variações de estrutura corporativa de capital se devem às variações setoriais, enquanto Mackay e Phillips (2005) obtiveram $\mathrm{R}^{2}$-ajustado de $13 \%$ em regressões com efeitos fixos de setor. Por sua vez, Copat (2009) percebeu diferenças na sensibilidade do endividamento a fatores setoriais entre empresas latino-americanas e americanas. Já Copat e Terra (2009) consideraram: Dispersão de Eficiência Tecnológica, Dispersão da Qualidade dos Produtos, Poder de Barganha dos Clientes, Poder de Barganha dos Fornecedores e Ciclo de Vida do setor. Ademais, seguindo Kayo e Kimura (2011), incluíram-se a Munificência, o Dinamismo e a Concentração setoriais.

Inicialmente, Maksimovic e Zechner (1991) argumentam que empresas com produção mais eficiente e cujos produtos têm maior qualidade apresentam maior rentabilidade, ao passo que empresas menos eficientes e cujos produtos têm menor qualidade indicam menor rentabilidade. Para equipararem seu retorno e seguirem competitivas no setor, os autores sugerem que essas empresas aumentem seu 
endividamento. $\mathrm{Na}$ ausência do benefício fiscal da dívida, a eficiência tecnológica e o nível de endividamento seriam irrelevantes. Porém o benefício fiscal da dívida incentiva as empresas a adotarem tecnologias menos eficientes. Dessa forma, a Dispersão da Eficiência Tecnológica e a Dispersão de Qualidade dos Produtos de um setor devem estar positivamente associadas com seu nível de endividamento.

Por sua vez, Kale e Shahrur (2007) argumentam que o Poder de Barganha dos Clientes e o Poder de Barganha dos Fornecedores devem apresentar relação positiva com Alavancagem. Para os autores, as firmas podem decidir aumentar seu endividamento como forma de diminuir o poder dos agentes interessados (stakeholders) não financeiros. Essencialmente, os autores assumem que as firmas podem utilizar o endividamento como escudo para a potencial extração futura de divisas por parte dos agentes interessados não financeiros. Em setores cujos clientes e fornecedores exercem pressão maior na empresa, portanto, o endividamento pode ser deliberadamente aumentado para que a empresa comprometa uma parcela de seus fluxos de caixa com os credores e sofra menos pressão das demais partes. Espera-se, portanto, relação positiva com o endividamento.

Contudo espera-se relação negativa entre o Ciclo de Vida do Setor e Alavancagem. Empresas em setores mais novos, potencialmente, têm um conjunto maior de investimentos a ser feito para suprir a demanda do setor. Tal conjunto de investimentos tem pouco valor para os credores se a empresa entrar em processo de falência. Nesse caso, de acordo com o tradeoff estático, empresas de tais setores conseguem captar menores proporções de dívida.

Incluíram-se, ainda, as variáveis Munificência (medida da disponibilidade dos recursos no setor), Dinamismo (volatilidade dos recursos disponíveis no setor) e Concentração do setor da mesma forma que Kayo e Kimura (2011). Setores com maior disponibilidade de recursos comportam maior crescimento das firmas que, dessa forma, apresentam maior Lucratividade. De acordo com a hipótese do tradeoff estático, Lucratividade e Alavancagem são positivamente relacionadas, ao passo que, segundo a hipótese da pecking order, Lucratividade e Alavancagem são negativamente relacionadas. Desse modo, o efeito de Munificência no nível de endividamento é ambíguo. Ressalta-se, no entanto, que Kayo e Kimura (2011) encontraram relação negativa. Por sua vez, para Simerly e Li (2000), em setores mais dinâmicos o risco é maior. Consequentemente, o financiamento via emissão de ações deveria ser preferível ao financiamento via emissão de dívidas porque diminui os custos de transação da empresa. Nesse caso, as firmas utilizam maiores proporções de recursos próprios e captam menores níveis de dívida. Finalmente, no modelo de Maksimovic (1988), as firmas de um mesmo setor entram em um equilíbrio que depende do número de participantes. Em setores com oligopólios (mais concentrados), o acordo é facilmente mantido e as empresas podem sustentar maior endividamento, ao passo que em setores mais competitivos o equilíbrio é mais instável e as firmas apresentam menor endividamento. Destaca-se que Mackay e Phillips (2005) encontraram relação negativa entre concentração e endividamento.

\section{Variáveis macroeconômicas}

No que tange às variáveis macroeconômicas, incluíram-se as seguintes variáveis: PIB per capita, Crescimento do PIB, Taxa de Inflação, Taxa Real de Juros e Variação Cambial. Inicialmente, seguindo Demirgüç-Kunt e Maksimovic (1999) e Jong, Kabir e Nguyen (2008), respectivamente, controlaram-se para o PIB per capita e Crescimento do PIB. Demirgüç-Kunt e Maksimovic (1999) sugerem que cerca de $40 \%$ das variáveis do financiamento via recursos de longo prazo pode ser explicado por diferenças do PIB entre os países de sua amostra. Por sua vez, Jong et al. (2008) utilizaram o Crescimento do PIB para controlar o impacto das condições econômicas gerais. Seus achados apontam para uma relação positiva com o endividamento. Kayo e Kimura (2011), porém, encontraram relação negativa e, por isso, sugerem que o Crescimento do PIB pode ser um agregado da Munificência setorial que provê maiores oportunidades de investimento para as firmas, o que explicaria tal relação.

Fan et al. (2012) sugerem que Taxas de Inflação mais altas, usualmente, estão relacionadas à maior incerteza na economia. Consequentemente, diminui-se o incentivo dos credores a financiar as 
necessidades de capital das empresas, de modo que se deva esperar relação negativa entre Taxa de Inflação e endividamento. Da mesma forma, altas na Taxa Real de Juros indicam maior incerteza na economia e apontam para maior custo de captação. Como resultado, espera-se relação negativa com Alavancagem. Kirch e Terra (2012) também controlaram para tais variáveis, porém utilizaram sua volatilidade, enquanto o presente estudo utilizou as variáveis em nível. Finalmente, Allayannis e Ofek (2001) observam que variações do câmbio podem alterar a competitividade das firmas pela mudança nos custos (receitas) de importação (exportação). Para controlar o nível de competitividade internacional das empresas, incluiu-se como variável de controle a Variação Cambial da moeda local.

\section{Desenvolvimento financeiro e qualidade institucional}

Em seu trabalho, Fan et al. (2012) verificaram relações positivas de desenvolvimento econômico, existência de um código de falência e nível de depósitos bancários com Alavancagem. Demirgüç-Kunt e Maksimovic (1999) e Giannetti (2003) encontraram, também, que a Qualidade Institucional favorece o endividamento. Giannetti (2003), da mesma forma, percebeu que menores índices de corrupção estão associados à menor Alavancagem. Por sua vez, Kirch e Terra (2012) investigaram o efeito de fatores (extraídos via Analise Fatorial) de Desenvolvimento Financeiro e Qualidade Institucional na Maturidade do endividamento de empresas sul-americanas. Seus resultados apontam a relação positiva entre Qualidade das Instituições e Maturidade, porém não significativa com o Desenvolvimento Financeiro. Tomando os resultados em conjunto, os autores sugerem que o Desenvolvimento Financeiro pode ser produto da Qualidade Institucional.

Por sua vez, Li et al. (2009) constataram que o desenvolvimento das instituições apresentou relação negativa com o acesso a recursos de maior prazo. Esses autores sublinham como possível explicação o fato de que o desenvolvimento institucional pode afetar o desenvolvimento dos mercados de ações e de dívidas de modo desigual. Para eles, os acionistas, por serem os beneficiários residuais, devem ser mais sensíveis a melhorias na proteção dos investidores que os credores; muito embora ambos se beneficiem da melhor proteção de seus interesses (La Porta, Lopez-de-Silanes, Shleifer, \& Vishny, 1998). Dessa forma, a Qualidade das Instituições pode afetar negativamente o nível de endividamento por aumentar a emissão de ações. Seu argumento é similar ao de Kirch e Terra (2012), na medida em que o desenvolvimento financeiro abrange o desenvolvimento do mercado acionário, porém Kirch e Terra (2012) não separam o efeito do mercado acionário na sua medida de Desenvolvimento Financeiro. Além disso, para capturar a relação emissão de ações versus emissão de dívida, uma medida de Alavancagem deve ser mais apropriada que uma medida de Maturidade do endividamento. Desse modo, os resultados do presente trabalho devem ser mais sensíveis ao desenvolvimento do mercado acionário que os resultados de Kirch e Terra (2012). Destaca-se, por fim, que Kayo e Kimura (2011) encontraram relação negativa entre o desenvolvimento do mercado acionário e endividamento. A descrição da Análise Fatorial empregada será apresentada no próximo item.

\section{Dados, Amostra, Análise Fatorial e Modelo Estatístico}

A amostra foi composta pelos seguintes países: Argentina, Brasil, Chile, Colômbia, México, Peru e Venezuela (adicionalmente, incluíram-se os EUA). De modo resumido, esses países são os que possuem as maiores economias da América Latina e, portanto, maior representatividade econômica. O período utilizado pela pesquisa se iniciou em 1996 e encerrou-se em 2009 (o ano de 1995 foi utilizado como base para a mensuração de algumas variáveis). Tal escolha foi necessária porque os dados disponíveis acerca de algumas variáveis relativas ao Desenvolvimento Financeiro são disponibilizados apenas para esse período específico. Ademais, as observações de empresas brasileiras representaram cerca de $40 \%$ das observações latino-americanas. Uma vez que esse país enfrentou altos índices de inflação até 1994, assim, a inclusão de períodos anteriores poderia impactar os resultados.

Essencialmente, a fonte dos dados contábeis utilizados foi a base Economática. Dessa base, foi extraída, ainda, a classificação setorial. No total, são 21 setores, dos quais foram excluídos: (a) o setor 
finanças e seguros e o setor fundos devido às suas peculiaridades em termos de tomada de capital externo; e (b) o setor outros, por não ser um segmento uniforme dentro da classificação da base. Os dados macroeconômicos, por sua vez, foram retirados de International Monetary Fund. Já os dados acerca dos fatores relacionados ao Desenvolvimento Financeiro e Qualidade das Instituições foram extraídos da fonte apontada por Beck, Demirgüç-Kunt e Levine (2010) e Kaufmann, Kraay e Mastruzzi (2009). Além disso, foi utilizado o procedimento de winsorização (winsorization) em 1\%, como medida para corrigir potenciais observações extremas (outliers).

\section{Fatores relativos ao desenvolvimento financeiro e qualidade das instituições}

De forma semelhante ao estudo de Kirch e Terra (2012), as variáveis do Desenvolvimento Financeiro e Qualidade das Instituições foram retiradas das bases World Bank Financial Structure e Governance Indicators Dataset. Ao todo, são 32 e seis variáveis disponibilizadas respectivamente. Para evitar multicolinearidade, procedeu-se à extração de um fator para cada grupo. Tal decisão permitiu a consolidação de grande parte da variabilidade de toda a base de dados e tornou possível a manutenção dos seus efeitos na variável dependente. Além disso, procedeu-se à Análise Fatorial para que fosse possível comparar os efeitos dos dois grupos de variáveis. Tal comparação seria impossível se fosse considerado o número desigual de variáveis dos grupos. Finalmente, a inclusão de um grande conjunto de variáveis através dos fatores extraídos mitiga o potencial viés de variável omitida.

Em ambos os casos, os dados disponibilizados estão em estrutura de painel. Como a Análise Fatorial requer que os dados estejam em apenas duas dimensões, os fatores foram extraídos ano a ano. No total, mais de 200 países compõem as bases. Convém salientar que foram utilizadas as observações de todos os países disponíveis. Extrair os fatores de uma amostra global é uma decisão empiricamente mais robusta que extrair o fator de uma amostra regional. Por exemplo, o coeficiente Beta do Capital Assets Pricing Model (CAPM) mede a sensibilidade de um ativo à carteira de mercado, que é perfeitamente diversificada. Caso fosse considerada como carteira de mercado apenas uma subamostra dos ativos disponíveis (por exemplo, de somente uma região ou um setor de atividade), o coeficiente Beta estimado representaria a sensibilidade dos retornos do ativo apenas àquele subconjunto dos ativos disponíveis (o que iria de encontro à premissa de diversificação perfeita). De forma análoga, deseja-se que a carga fatorial (Beta) extraída via análise fatorial represente a sensibilidade do Ambiente Institucional a uma amostra global (e não apenas à região latino-americana). Desse modo, incluíram-se todos os países disponíveis nas bases de dados e entende-se que os fatores extraídos são representativos das variáveis ao nível global.

Em relação ao Desenvolvimento Financeiro, algumas das 32 variáveis apresentavam número criticamente baixo de observações ou observações faltantes para os países em análise. Tais variáveis foram excluídas da análise. Como resultado, foram selecionadas 16 variáveis ${ }^{(1)}$. Apesar de se ter selecionado metade das variáveis, elas representam $66 \%$ do número total de observações. Na média, o número de observações anual foi de 109 (mínimo 89), o que resulta, aproximadamente, 6,83 e 5,56 observações por variável, respectivamente. A estatística Kaiser-Meyer-Olkin (KMO) média foi 0,79, o que mostra a boa adequação do fator aos dados. Além disso, a média do autovalor (Eigenvalue) foi 6,1 e explica 38\% da variância. Também se observa que não se incluíram, no fator, variáveis diretamente relacionadas ao Mercado de Ações.

Em relação à Qualidade das Instituições, não foi necessário qualquer procedimento de exclusão de variáveis ${ }^{(2)}$. Na média, o número anual de observações foi 194, resultando, aproximadamente, 32 observações por variável. A estatística KMO média foi $0,90, \log$ o, o fator extraído se mostra adequado. Por sua vez, a média do autovalor foi 5,1, o que explica $86 \%$ da variância. Percebe-se que não houve cargas fatoriais destacadamente superiores às demais; nesse caso, entende-se que o fator extraído representa as seis variáveis de forma conjunta.

A Tabela 1 elenca os valores médios dos fatores extraídos. Em relação ao Desenvolvimento Financeiro, muito embora próxima de zero, a média dos valores do Chile foi a única positiva $(0,02)$, entre os países latinos. A seguir, posicionam-se Brasil $(-0,12)$, Argentina $(-0,48)$, Colômbia $(-0,53)$, 
México $(-0,55)$, Peru $(-0,56)$ e Venezuela $(-0,69)$. No que tange à Qualidade das Instituições, novamente, o valor encontrado para o Chile se mostra superior aos de seus vizinhos, a média foi de 1,26, aproximadamente. A seguir, posicionam-se Brasil $(0,03)$, México (-0,03), Argentina (-0,14), Peru (0,30), Colômbia $(-0,53)$ e Venezuela $(-0,89)$. Por fim, percebeu-se que os Estados Unidos apresentaram valores médios maiores em ambos os casos. Em especial, o fator do Desenvolvimento Financeiro apresentou valor, destacadamente, superior aos demais.

Tabela 1

Descrição dos Fatores Desenvolvimento Financeiro e Qualidade das Instituições

\begin{tabular}{lccccccccc} 
& \multicolumn{3}{c}{ Desenvolvimento Financeiro } & \multicolumn{3}{c}{ Qualidade das Instituições } \\
\cline { 2 - 9 } & Média & Desvio padrão & Máximo & Mínimo & Média & Desvio padrão & Máximo & Mínimo \\
\hline Argentina & $-0,48$ & 0,14 & $-0,33$ & $-0,79$ & $-0,14$ & 0,33 & 0,41 & $-0,71$ \\
Brasil & $-0,12$ & 0,06 & $-0,02$ & $-0,21$ & 0,03 & 0,08 & 0,21 & $-0,07$ \\
Chile & 0,02 & 0,19 & 0,26 & $-0,21$ & 1,26 & 0,09 & 1,38 & 1,08 \\
Colômbia & $-0,53$ & 0,24 & $-0,17$ & $-0,81$ & $-0,53$ & 0,14 & $-0,32$ & $-0,69$ \\
México & $-0,55$ & 0,08 & $-0,39$ & $-0,65$ & $-0,03$ & 0,12 & 0,17 & $-0,15$ \\
Peru & $-0,56$ & 0,10 & $-0,40$ & $-0,71$ & $-0,30$ & 0,07 & $-0,21$ & $-0,45$ \\
Venezuela & $-0,69$ & 0,14 & $-0,41$ & $-0,93$ & $-0,89$ & 0,36 & $-0,40$ & $-1,39$ \\
Estados Unidos & 1,14 & 0,40 & 1,73 & 0,54 & 1,49 & 0,11 & 1,64 & 1,30 \\
\hline
\end{tabular}

Reconhecidamente, as médias dos fatores do Chile se revelaram acima dos vizinhos latinoamericanos. Diversas características do seu ambiente econômico e social podem explicar tais circunstâncias. Por exemplo, segundo a The Heritage Foundation, o Chile foi considerado a sétima economia mais livre em 2014, enquanto o México e o Brasil, por exemplo, foram consideradas a $55^{\mathrm{a}}$ e $114^{a}$ economias, respectivamente. Para Knebel, Schmidt-Hebbel e Thunert (2011), a liberdade política é maior e a corrupção é menor no Chile do que nos demais países estudados. Além disso, segundo dados da The Doing Business Project, abrir um novo negócio no Chile leva em média 5,5 dias, ao passo que no Peru leva 25 e, no Brasil, 104. Em resumo, o Ambiente Institucional do Chile parece ser mais avançado que o de seus vizinhos de continente, de acordo com várias fontes. $\mathrm{O}$ indicador deste estudo foi, portanto, consistente com essas evidências.

\section{Modelo estatístico}

Como modelo estatístico, foi utilizado o Modelo Linear Hierárquico, da mesma forma que Kayo e Kimura (2011). Para o aninhamento (nesting), foi executada a mesma divisão elaborada pelos autores; o primeiro nível foi composto pela variável tempo; o segundo, pelas variáveis específicas da firma; e o terceiro, pelas variáveis relativas ao setor e variáveis em nível de país (macroeconômicas, Desenvolvimento Financeiro e Institucionais). Tomou-se o cuidado de não aninhar as variáveis setoriais e as variáveis de país, na medida em que uma determinada empresa $f$ pode estar no setor $s$ do país $p$, porém não estará no mesmo setor $s$ do país $p$ '. Por fim, o método de estimação dos parâmetros foi a estimativa por Máxima Verossimilhança (MLE) e os dados estão em estrutura de painel não balanceado.

\section{O modelo vazio}

Um dos recursos obtidos a partir do modelo utilizado é a decomposição da variância da variável dependente. Segundo Rabe-Hesketh e Skrondal (2008), "In clustered data, it is usually important to allow for dependence or correlations among the responses observed belonging the same cluster". Nesse caso, "variance-components models are designed to model and estimate such within-cluster correlations" (p. 51). Tal efeito motivou a execução da presente etapa. 
Nessa etapa inicial, não foram incluídas as variáveis independentes e foram utilizados apenas dados da variável dependente. Seu objetivo era, exclusivamente, identificar a importância relativa de cada nível nas variações da Alavancagem. Como primeiro passo, assume-se que a Alavancagem $\left(A L A V_{t f s p}\right)$ do ano $t$, da firma $f$ que faz parte do setor s e do país p é uma função da Alavancagem média da firma $\mathrm{f}$ ao longo do tempo ( $\left.\beta_{\text {ofsp }}\right)$ mais um erro $\left(\varepsilon_{\mathrm{tfsp}}\right)$ que tem distribuição normal, média zero e variância $\sigma^{2}$ e que representa a variância ao longo do tempo.

$$
\mathrm{ALAV}_{\mathrm{tfsp}}=\beta_{0 \mathrm{fsp}}+\varepsilon_{\mathrm{tfsp}}
$$

No segundo nível, a Alavancagem média ao longo do tempo da firma f, que faz parte do setor s e do país $\mathrm{p}\left(\beta_{0 \mathrm{fsp}}\right)$, é uma função da Alavancagem média do setor s e do país $\mathrm{p}\left(\gamma_{00 \mathrm{sp}}\right)$ mais um erro $\left(r_{0 f s p}\right)$, que representa a variância entre as firmas.

$$
\beta_{\text {ofsp }}=\gamma_{00 \mathrm{sp}}+\mathrm{r}_{\mathrm{ofsp}}
$$

Finalmente, no terceiro nível, a Alavancagem média do setor $\mathrm{s}$ e do país $\mathrm{p}\left(\gamma_{00 \mathrm{sp}}\right)$, que passa a ser aleatória, é uma função da Alavancagem média de toda a amostra $\left(\delta_{0000}\right)$ mais um erro aleatório $\left(\mathrm{u}_{00 \mathrm{sp}}\right)$, que representa a variância do setor $\mathrm{s}$ e do país $\mathrm{p}$.

$$
\gamma_{00 s p}=\delta_{0000}+s_{00 s 0}+t_{000 p}+u_{00 s p}
$$

Nesse nível, porém, são adicionados dois novos elementos: um erro aleatório $\left(\mathrm{s}_{00 \mathrm{k} 0}\right)$, que representa a variância entre os setores; e um erro aleatório $\left(t_{0001}\right)$, que representa a variância entre os países. Consolidando as três equações, tem-se:

$$
\mathrm{ALAV}_{\mathrm{tfsp}}=\delta_{0000}+\mathrm{s}_{00 \mathrm{~s} 0}+\mathrm{t}_{000 \mathrm{p}}+\mathrm{u}_{00 \mathrm{sp}}+\mathrm{r}_{0 \mathrm{fsp}}+\varepsilon_{\mathrm{tfsp}}
$$

Desse modo, a Alavancagem $\mathrm{ALAV}_{\mathrm{tfsp}}$ do ano t, da firma f que faz parte do setor s e do país p é uma função da Alavancagem média de toda a amostra $\delta_{0000}$; de um erro aleatório $\mathrm{u}_{00 \mathrm{sp}}$, que representa a variância de um termo de interação entre o setor s e o país $p$; de um erro $\mathrm{s}_{00 \mathrm{~s} 0}$, que representa a variância entre os setores; de um erro $t_{000 p}$, que representa a variância entre os países; de um erro $r_{0 f s p}$, que representa a variância entre as firmas; e de erro $\varepsilon_{\text {tfsp }}$, que representa a variância ao longo do tempo. A variância dos erros descritos indica a importância relativa do nível de estudo na variância da Alavancagem.

\section{A inclusão das variáveis independentes}

Após a decomposição da variância, com o objetivo de se analisar a significância dos coeficientes das equações seguintes, procede-se à inclusão das variáveis independentes. A inclusão é feita gradualmente, conforme as equações 1,2 e 3 são reestimadas. Dessa forma, o primeiro passo é reestimar a equação 1 incluindo as variáveis específicas da firma, a saber: Tangibilidade $\left(\mathrm{TG}_{\mathrm{tfsp}}\right)$, Tamanho $\left(\mathrm{TA}_{\mathrm{tfsp}}\right)$, Carga Fiscal $\left(\mathrm{CF}_{\mathrm{tfsp}}\right)$, Lucratividade $\left(\mathrm{LU}_{\mathrm{tfsp}}\right)$, Liquidez $\left(\mathrm{LI}_{\mathrm{tfsp}}\right)$, Oportunidades de Crescimento $\left(\mathrm{OC}_{\mathrm{tfsp}}\right)$ e $\mathrm{ADR}$ 's $\left(\mathrm{ADR}_{\mathrm{tfsp}}\right)$. Adicionou-se, ainda, uma variável binária $\left(\mathrm{ANO}_{\mathrm{tfsp}}\right)$ para cada ano da análise, exceto o primeiro.

$$
\begin{aligned}
& \mathrm{ALAV}_{\mathrm{tfsp}}^{\prime}=\beta_{0 \mathrm{fsp}}^{\prime}+\beta_{1 \mathrm{fsp}} \cdot \mathrm{ANO}_{\mathrm{tfsp}}+\beta_{2 \mathrm{fsp}} \cdot \mathrm{TG}_{\mathrm{tfsp}}+\beta_{3 \mathrm{fsp}} \cdot \mathrm{TA}_{\mathrm{tfsp}}+\beta_{4 \mathrm{fsp}} \cdot \mathrm{CF}_{\mathrm{tfsp}}+ \\
& \beta_{5 f s p} \cdot \mathrm{LU}_{\mathrm{tfsp}}+\beta_{6 \mathrm{fsp}} \cdot \mathrm{LI}_{\mathrm{tfsp}}+\beta_{7 \mathrm{fsp}} \cdot \mathrm{OC}_{\mathrm{tfsp}}+\beta_{8 \mathrm{fsp}} \cdot \mathrm{ADR}_{\mathrm{tfsp}}+\varepsilon_{\mathrm{tfsp}}{ }^{\prime}
\end{aligned}
$$

Na sequência, a equação 2 é reestimada. Incluem-se as variáveis relativas aos setores, a saber: Munificência ( $\left.\mathrm{MU}_{\text {oosp }}\right)$, Dinamismo (DI $\left.\mathrm{Dosp}_{\mathrm{osp}}\right)$, Concentração $\left(\mathrm{HH}_{\text {oosp }}\right)$, Ciclo de Vida do Setor $\left(\mathrm{CV}_{\text {oosp }}\right)$, Dispersão da Eficiência Tecnológica ( $\mathrm{DT}_{\text {oosp }}$ ), Dispersão da Qualidade dos Produtos do Setor ( $\mathrm{DQ}_{\text {oosp }}$ ), Poder de Barganha dos Clientes ( $\left.\mathrm{PC}_{\text {oosp }}\right)$ e Poder de Barganha dos Fornecedores $\left(\mathrm{PF}_{\text {oosp }}\right)$. 


$$
\begin{aligned}
& \beta_{0 \text { fsp }}^{\prime}=\gamma_{00 s p}^{\prime}+\gamma_{01 s p} \cdot \mathrm{MU}_{00 \mathrm{sp}}+\gamma_{02 \mathrm{sp}} \cdot \mathrm{DI}_{00 \mathrm{sp}}+\gamma_{03 \mathrm{sp}} \cdot \mathrm{HH}_{00 \mathrm{sp}}+\gamma_{04 \mathrm{sp}} \cdot \mathrm{CV}_{00 \mathrm{sp}}+ \\
& \gamma_{05 \mathrm{sp}} \cdot \mathrm{DT}_{00 \mathrm{sp}}+\gamma_{06 \mathrm{sp}} \cdot \mathrm{DQ}_{00 \mathrm{sp}}+\gamma_{07 \mathrm{sp}} \cdot \mathrm{PC}_{00 \mathrm{sp}}+\gamma_{08 \mathrm{sp}} \cdot \mathrm{PF}_{00 \mathrm{sp}}+\mathrm{r}_{0 \mathrm{fsp}}^{\prime}
\end{aligned}
$$

Finalmente, a equação 3 é reestimada. Incluem-se, nesse caso, as variáveis em nível de país, a saber: Crescimento Real do PIB $\left(\mathrm{CRP}_{000 \mathrm{p}}\right)$, PIB per Capita $\left(\mathrm{PpC}_{000 \mathrm{p}}\right)$, Taxa de Inflação $\left(\mathrm{TI}_{000 \mathrm{p}}\right)$, a Variação Cambial $\left(\mathrm{VC}_{000 \mathrm{p}}\right)$ a Taxa Real de Juros $\left(\mathrm{TJ}_{000 \mathrm{p}}\right)$ fator de Desenvolvimento Financeiro $\left(\mathrm{DF}_{000 \mathrm{p}}\right)$ e fator de Qualidade das Instituições (QI $\left.{ }_{000 \mathrm{p}}\right)$. Para mitigar o potencial efeito da endogeneidade entre Desenvolvimento Financeiro e a Variável dependente, defasou-se o fator extraído em uma unidade de tempo.

$$
\begin{aligned}
& \gamma_{00 \mathrm{sp}}^{\prime}=\delta_{0000}^{\prime}+\delta_{0001} \cdot C R P_{000 p}+\delta_{0002} \cdot P p C_{000 p}+\delta_{0003} \cdot T I_{000 p}+\delta_{0004} \cdot V C_{000 p}+ \\
& \delta_{0005} \cdot T J_{000 p}+\delta_{0006} \cdot D F_{000 p}+\delta_{0007} \cdot Q I_{000 p}+s_{00 \mathrm{~s} 0}^{\prime}+t_{000 \mathrm{p}}^{\prime}+u_{00 \mathrm{sp}}^{\prime}
\end{aligned}
$$

Consolidando as equações 5, 6 e 7, tem-se a equação 8:

$$
\begin{aligned}
& \mathrm{ALAV}_{\mathrm{tfsp}}^{\prime}=\delta_{0000}^{\prime}+\delta_{0001} \cdot \mathrm{CRP}_{000 \mathrm{p}}+\delta_{0002} \cdot \mathrm{PpC}_{000 \mathrm{p}}+\delta_{0003} \cdot \mathrm{TI}_{000 \mathrm{p}}+\delta_{0004} \cdot \mathrm{VC}_{000 \mathrm{p}}+ \\
& \delta_{0005} \cdot \mathrm{TJ}_{000 \mathrm{p}}+\delta_{0006} \cdot \mathrm{DF}_{000 \mathrm{p}}+\delta_{0007} \cdot \mathrm{QI}_{000 \mathrm{p}}+s_{00 \mathrm{~s} 0}^{\prime}+t_{000 \mathrm{p}}^{\prime}+u_{00 \mathrm{sp}}^{\prime}+\gamma_{01 \mathrm{sp}} \cdot \mathrm{MU}_{00 \mathrm{sp}}+ \\
& \gamma_{02 \mathrm{sp}} \cdot \mathrm{DI}_{00 \mathrm{sp}}+\gamma_{03 \mathrm{sp}} \cdot \mathrm{HH}_{00 \mathrm{sp}}+\gamma_{04 \mathrm{sp}} \cdot \mathrm{CV}_{00 \mathrm{sp}}+\gamma_{05 \mathrm{sp}} \cdot \mathrm{DT}_{00 \mathrm{sp}}+\gamma_{06 \mathrm{sp}} \cdot \mathrm{DQ}_{00 \mathrm{sp}}+ \\
& \gamma_{07 \mathrm{sp}} \cdot \mathrm{PC}_{00 \mathrm{sp}}+\gamma_{08 \mathrm{sp}} \cdot \mathrm{PF}_{00 \mathrm{sp}}+\mathrm{r}_{0 \mathrm{fsp}}^{\prime}+\beta_{1 \mathrm{fsp}} \cdot \mathrm{ANO}_{\mathrm{tfsp}}+\beta_{2 \mathrm{fsp}} \cdot \mathrm{TG}_{\mathrm{tfsp}}+\beta_{3 \mathrm{fsp}} \cdot \mathrm{TA}_{\mathrm{tfsp}}+ \\
& \beta_{4 \mathrm{fsp}} \cdot \mathrm{CF}_{\mathrm{tfsp}}+\beta_{5 \mathrm{fsp}} \cdot \mathrm{LU}_{\mathrm{tfsp}}+\beta_{6 \mathrm{fsp}} \cdot \mathrm{LI}_{\mathrm{tfsp}}+\beta_{7 \mathrm{fsp}} \cdot \mathrm{OC}_{\mathrm{tfsp}}+\beta_{8 \mathrm{fsp}} \cdot \mathrm{ADR}_{\mathrm{tfsp}}+\varepsilon_{\mathrm{tfsp}}^{\prime}
\end{aligned}
$$

Nota-se que, na equação 8, a Alavancagem é função das variáveis de todos os grupos determinantes simultaneamente: específicos da firma, setoriais e ao nível de país (macroeconômicos, Desenvolvimento Financeiro e Qualidade das Instituições).

\section{Variáveis dependentes e independentes}

Seguindo Rajan e Zingales (1995), Almazan e Molina (2005), Kale e Shahrur (2007) e Céspedes González e Molina (2010), foi utilizado o quociente dívida total dividida pelo somatório de dívida total e capital próprio (AL1) como medida do endividamento da firma. Observa-se, que o resultado da subtração entre a unidade e a medida de Alavancagem representa a proporção de capital próprio da empresa na sua estrutura de capital.

Do mesmo modo que Rajan e Zingales (1995), Almazan e Molina (2005), Kale e Shahrur (2007), Jong et al. (2008) e Kayo e Kimura (2011), Tangibilidade é o quociente Imobilizado/Ativo Total. Lucratividade é o quociente EBITDA/Ativo Total (similar a Almazan \& Molina, 2005). Seguindo Guedes e Opler (1996), Stohs e Mauer (1996), Ozkan (2000) e Terra (2011), incluiu-se a Carga Fiscal paga pelas firmas. Mediu-se essa variável pelo quociente Tributos Pagos/Ativo Total. (O nível de Oportunidades de Crescimento foi medido pelo Market-to-Book, da mesma forma que Barclay e Smith (1995), Stohs e Mauer (1996), Guedes e Opler (1996), Ozkan (2000), Antoniou, Guney e Paudyal (2006), Terra (2011) e Kirch e Terra (2012). Por sua vez, o Tamanho é medido pelo Logaritmo Natural da Receita de Vendas (Antoniou, Guney, \& Paudyal, 2006; Kirch \& Terra, 2012; Ozkan, 2000; Stohs \& Mauer, 1996; Terra, 2011). Liquidez é mensurada por Ativos Correntes/Ativo Total (medida análoga a Antoniou et al., 2006; Guney \& Ozkan, 2005; Terra, 2011). Adicionalmente, incluiu-se uma variável binária com valor 1 para as empresas com ADRs emitidas; e zero, em caso contrário.

Segundo Copat e Terra (2009), tecnologias eficientes requerem alto investimento e exigem baixo custo de produção. Dessa forma, a Dispersão da Eficiência Tecnológica foi medida pelo desvio padrão setorial de Imobilizado/Custo do Produto Vendido. Analogamente, produtos de maior qualidade oferecem maiores margens brutas. Desse modo, a Dispersão da Qualidade dos Produtos do setor foi medida pelo desvio padrão setorial de Lucro Bruto/Receita Operacional Líquida. Empresas cujos clientes e fornecedores têm mais poder de barganha devem ser obrigadas a oferecer maiores prazos para recebimento e pagamento, respectivamente. Assim, mediu-se o Poder de Barganha dos Clientes pela mediana setorial do quociente Clientes de Curto Prazo/Receita Operacional Líquida $x$ 360. Já o Poder de Barganha dos Fornecedores é a mediana setorial do quociente (Fornecedores de Curto Prazo/Receita 
Operacional Líquida $X$ 360. Por fim, o Ciclo de Vida do Setor é a mediana do quociente (receita operacional líquida $t_{t} /$ receita operacional líquida $\left.a_{t-1}\right)-1$ ).

De acordo com Kayo e Kimura (2011), calculou-se Munificência da seguinte forma: (a) fez-se a regressão do tempo contra as vendas do setor dos cinco anos anteriores ao período em análise; e (b) dividiu-se o coeficiente angular pela média das vendas do setor do período. O Dinamismo foi medido pelo erro padrão do coeficiente angular da regressão de Munificência dividido pela média das vendas do setor. A Concentração foi mensurada pela soma dos quadrados das participações de mercado das empresas do setor.

Por fim, de modo análogo a Demirgüç-Kunt e Maksimovic (1998, 1999) e Jong et al. (2008); Crescimento Real do PIB foi medido por $\left(P I B_{t} / P I B_{t-1}\right) /\left(\right.$ índice deflator do PIB $B_{t} /$ índice deflator do $\left.P I B_{t-1}\right)$. PIB per capita é igual ao quociente $P I B /$ população e Taxa de Inflação

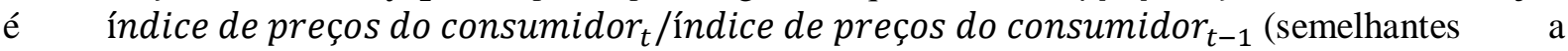
Demirgüç-Kunt \& Maksimovic; 1998, 1999). Variação Cambial é ((moeda nacional/SDR $)_{t} /$ $\left.(\text { moeda nacional/SDR })_{t-1}\right)$, e a Taxa Real de Juros é $((1+$ taxa de juros de captação $) /(1+$ taxa de inflação) - 1).

\section{Resultados}

\section{Decomposição da variância}

A partir da decomposição da variância da variável dependente, obtiveram-se os resultados apresentados na Tabela 2. Percebe-se que as variações entre as empresas e as variações ao longo do tempo são as maiores fontes de variabilidade da Alavancagem. Juntas, representam, aproximadamente, $86 \%$ das variações na amostra AL/EUA e em torno de $92 \%$ na América Latina. Em seguida, na amostra AL/EUA, tem-se que as variações do termo de interação entre país e setor representam em torno de $11 \%$ das variações de AL1. Uma vez que os Estados Unidos foram excluídos da amostra, a representatividade cai para $4 \%$. Esse resultado sugere que, conforme os países se tornam mais homogêneos, a representatividade do terceiro nível diminui. Ou, ainda, para estudos de estrutura de capital, quanto mais heterogênea for a amostra estudada, mais relevante se torna incluir variáveis em nível de país.

Tabela 2

\section{Decomposição da Variância}

\begin{tabular}{lcc}
\hline Nível & Amostra AL/EUA & América Latina \\
\hline País & $2,26 \%$ & $2,36 \%$ \\
Setor & $1,54 \%$ & $1,61 \%$ \\
Interação entre País e Setor & $10,62 \%$ & $3,90 \%$ \\
Empresa & $47,68 \%$ & $48,64 \%$ \\
Tempo & $37,90 \%$ & $43,49 \%$ \\
\hline Total & $\mathbf{1 0 0 \%}$ & $\mathbf{1 0 0 \%}$ \\
\hline Observações & 13.651 & 5.559 \\
\hline
\end{tabular}

Procedeu-se, ainda, à decomposição da variância em cada um dos países de modo isolado; a Tabela 3 apresenta os resultados. Novamente, os dados obtidos sugerem que as variações entre as empresas e ao longo do tempo são as maiores fontes de variações na Alavancagem. Contudo variações entre os setores não podem, majoritariamente, ser desconsideradas. Por exemplo, na Venezuela, o 
percentual de importância relativa dos setores foi de aproximadamente 11\%; e, nos Estados Unidos, chegou próximo a $21 \%$. No caso das empresas brasileiras, identificou-se que o terceiro nível influenciou 4,28\% da medida de Alavancagem. Tal valor é consideravelmente baixo, porém é próximo do obtido em empresas argentinas e mais relevante que para empresas chilenas.

Tabela 3

Decomposição da Variância por País

\begin{tabular}{ccccccccc}
\hline Nível & Argentina & Brasil & Chile & Colômbia & México & Venezuela & Peru & Estados Unidos \\
\hline Setor & $4,28 \%$ & $4,79 \%$ & $0,94 \%$ & $2,87 \%$ & $1,52 \%$ & $10,89 \%$ & $0,00 \%$ & $20,98 \%$ \\
Empresa & $47,84 \%$ & $51,17 \%$ & $50,28 \%$ & $35,37 \%$ & $61,80 \%$ & $36,52 \%$ & $51,73 \%$ & $46,35 \%$ \\
Tempo & $47,88 \%$ & $44,05 \%$ & $48,78 \%$ & $61,75 \%$ & $36,69 \%$ & $52,59 \%$ & $48,27 \%$ & $32,67 \%$ \\
\hline Total & $\mathbf{1 0 0 \%}$ & $\mathbf{1 0 0 \%}$ & $\mathbf{1 0 0 \%}$ & $\mathbf{1 0 0 \%}$ & $\mathbf{1 0 0 \%}$ & $\mathbf{1 0 0 \%}$ & $\mathbf{1 0 0 \%}$ & $\mathbf{1 0 0 \%}$ \\
\hline Observações & 656 & 2.417 & 644 & 111 & 985 & 531 & 186 & 8.092 \\
\hline
\end{tabular}

\section{Análise multinível}

Os resultados da análise multinível são apresentados na Tabela 4. De modo majoritário, os resultados das variáveis específicas da firma confirmam diversas das previsões das hipóteses teóricas relacionadas ao tema. Encontrou-se relação positiva entre o nível de utilização de recursos de terceiros e (a) o nível de ativos tangíveis (p-valor < 0,05), e (b) o tamanho da firma (p-valor < 0,01), o que confirma a hipótese teórica do trade-off estático (Titman \& Wessels, 1988) e corrobora os resultados de Jong et al. (2008) e Kayo e Kimura (2011). Resumidamente, empresas maiores e com mais ativos tangíveis apresentaram maiores níveis de endividamento. Além disso, a medida de Oportunidades de Crescimento apresentou relação negativa ( $\mathrm{p}$-valor $<0,01$ ) tanto na amostra AL/EUA quanto apenas com as empresas latino-americanas. Tal resultado sustenta a hipótese do tradeoff estático e da Teoria da Agência e indica que Oportunidades de Crescimento não são boas garantias reais, de modo que as empresas se endividam menos.

Tabela 4

Análise Multinível

\begin{tabular}{lcccccc} 
& \multicolumn{3}{c}{ Amostra AL/EUA } & \multicolumn{3}{c}{ América Latina } \\
\cline { 2 - 7 } Var. Independentes & I & II & III & I & II & III \\
Variáveis binárias para anos & Sim & Sim & Sim & Sim & Sim & Sim \\
Constante & $0,15^{* * *}$ & $0,16^{* * *}$ & $0,16^{* * *}$ & $0,18^{* *}$ & 0,08 & $0,15^{* *}$ \\
\hline Variáveis em nível de firma: & & & & & & \\
\hline Tangibilidade & $0,04^{* *}$ & $0,04^{* *}$ & $0,04^{* *}$ & $0,06^{* *}$ & $0,06^{* *}$ & $0,06^{* *}$ \\
Lucratividade & $-0,32^{* * *}$ & $-0,32^{* * *}$ & $-0,32^{* * *}$ & $-0,46^{* * *}$ & $-0,46^{* * *}$ & $-0,46^{* * *}$ \\
Carga fiscal & $-0,98^{* * *}$ & $-0,94^{* * *}$ & $-0,97^{* * *}$ & $-1,16^{* * *}$ & $-1,18^{* * *}$ & $-1,16^{* * *}$ \\
Op. de crescimento & $-0,03^{* * *}$ & $-0,03^{* * *}$ & $-0,03^{* * *}$ & $-0,07^{* * *}$ & $-0,07^{* * *}$ & $-0,07^{* * *}$ \\
Tamanho & $0,02^{* * *}$ & $0,02^{* * *}$ & $0,02^{* * *}$ & $0,03^{* * * *}$ & $0,03^{* * *}$ & $0,03^{* * *}$ \\
Liquidez & $-0,07^{* * *}$ & $-0,07^{* * *}$ & $-0,07^{* * *}$ & $-0,05^{*}$ & $-0,04$ & $-0,05^{*}$ \\
ADR & 0,00 & 0,00 & $-0,01$ & $-0,01$ & $-0,02$ & $-0,02$ \\
\hline
\end{tabular}


Tabela 4 (continuação)

\begin{tabular}{lcccccc} 
& \multicolumn{3}{c}{ Amostra AL/EUA } & \multicolumn{3}{c}{ América Latina } \\
\cline { 2 - 7 } Variáveis Setoriais: & & & & & & \\
\hline Munificência & $-0,05^{* * *}$ & $-0,05^{* * *}$ & $-0,05^{* * *}$ & $-0,05^{* *}$ & $-0,05^{* *}$ & $-0,05^{* *}$ \\
Dinamismo & $0,07^{* * *}$ & $0,06^{* *}$ & $0,07^{* * *}$ & 0,03 & 0,03 & 0,03 \\
Concentração & $0,00^{*}$ & $0,00^{*}$ & $0,00^{* *}$ & 0,00 & 0,00 & 0,00 \\
Ciclo de Vida do Setor & $-0,01$ & $-0,01$ & $-0,01$ & $-0,05$ & $-0,04$ & $-0,05$ \\
Dispersão da Eficiência Tecnológica & $0,00^{* * *}$ & $0,00^{* * *}$ & $0,00^{* * *}$ & 0,00 & 0,00 & 0,00 \\
Dispersão da Qualidade dos Produtos & 0,01 & 0,02 & 0,01 & $-0,03$ & $-0,04$ & $-0,04$ \\
Poder de Barganha dos Clientes & $0,00^{* *}$ & $0,00^{* *}$ & $0,00^{* * *}$ & $0,00^{* *}$ & $0,00^{* *}$ & $0,00^{* *}$ \\
Poder de Barganha dos Fornecedores & $0,00^{* *}$ & $0,00^{* * *}$ & $0,00^{* *}$ & $0,00^{* *}$ & $0,00^{* *}$ & $0,00^{* *}$ \\
\hline Variáveis Macroeconômicas: & & & & & & \\
\hline PIB per capita & $0,00^{* * *}$ & $0,00^{* * *}$ & $0,00^{* * *}$ & $0,00^{* *}$ & 0,00 & $0,00^{* *}$ \\
Crescimento do PIB & 0,09 & $-0,09$ & 0,01 & 0,05 & 0,12 & 0,04 \\
Taxa de Inflação & $-0,13^{* * *}$ & $-0,07$ & $-0,16^{* * *}$ & $-0,14^{*}$ & $-0,15^{* *}$ & $-0,17^{* *}$ \\
Taxa Real de Juros & $0,16^{* * *}$ & $0,10^{* * *}$ & $0,10^{* * *}$ & $0,14^{* * *}$ & $0,13^{* * *}$ & $0,11^{* *}$ \\
Variação Cambial & 0,00 & $-0,01$ & $-0,01$ & $-0,01$ & $-0,02$ & $-0,02$ \\
\hline Fatores extraídos: & & & & & & \\
\hline Desenvolvimento Financeiro (defasado) & $-0,06^{* * *}$ & & $-0,06^{* * *}$ & $0,13^{* * *}$ & & $0,11^{* * *}$ \\
Qualidade das Instituições & & $-0,07^{* * *}$ & $-0,07^{* * *}$ & & $-0,05^{* *}$ & $-0,05^{* * *}$ \\
\hline AIC & -14954 & -15228 & -15290 & -3601 & -3320 & -3605 \\
BIC & -14666 & -14939 & -14994 & -3352 & -3071 & -3350 \\
\hline
\end{tabular}

Nota. $* * *, * * \mathrm{e} *$ indicam significância de $1 \%, 5 \%$ e $10 \%$, respectivamente.

As relações de Lucratividade ( $\mathrm{p}$-valor $<0,01)$ e Liquidez ( $\mathrm{p}$-valor $<0,10$ ) com o endividamento, por sua vez, confirmam a hipótese teórica da pecking order: todos os sinais dos coeficientes foram negativos. Tais resultados corroboram os achados de Harris e Raviv (1991), Giannetti (2003) e Kayo e Kimura (2011). Segundo essa hipótese teórica, os gestores, a fim de evitar a emissão de títulos desvalorizados, preferem utilizar o capital gerado internamente para o financiamento dos investimentos da firma. Consequentemente, empresas com maior Lucratividade e maior nível de Liquidez terão de recorrer à dívida apenas esporadicamente, de modo que seus níveis de endividamento sejam mais baixos. $\mathrm{O}$ coeficiente de Carga Fiscal apresentou p-valor $<0,01 \mathrm{em}$ todos os casos. No entanto seu sinal foi negativo, o que contraria a hipótese do trade-off estático e o trabalho de Fan et al. (2012). Uma possível explicação é que os autores consideraram as diferenças das alíquotas entre os países de sua amostra, ao passo que a medida em foco não considera tais diferenças. Além disso, sua amostra tem maior heterogeneidade que a amostra do presente trabalho, o que pode ter influenciado os resultados. Destacase, ainda, que Jong et al. (2008), também, encontraram resultados contrastantes (a relação foi negativa na maior parte dos casos, porém não foi conclusiva). Por fim, o coeficiente da variável binária para o lançamento de ADRs não foi significativamente diferente de zero em nenhuma das amostras.

No que tange às variáveis específicas do setor, a relação entre Alavancagem e Munificência foi negativa ( $\mathrm{p}$-valor $<0,05$ ), o que suporta a pecking order e converge com os resultados de Kayo e Kimura (2011). Há evidências, portanto, de que empresas que operam em setores com maior disponibilidade de recursos necessitam de menores proporções de capital de terceiros para suas atividades. A medida de Dinamismo apresentou relação positiva (na amostra AL/EUA, p-valor < 0,05), resultado contrário ao argumento de Simerly e Li (2000). Uma potencial explicação para a relação positiva é o fato de que em 
setores com maior volatilidade dos recursos disponíveis e, portanto, com maior risco, os acionistas aumentam o endividamento da firma com o objetivo de capturar o risco favorável (upside risk) setorial. No entanto, na amostra apenas com empresas latino-americanas, os coeficientes não foram distintos de zero, o que torna os resultados inconclusivos. A Concentração setorial apresentou relação positiva (pvalor < 0,10) na amostra AL/EUA, o que contraria Mackay e Phillips (2005), porém foi insignificante na amostra latino-americana.

Os coeficientes da Dispersão da Eficiência Tecnológica apresentaram relação positiva (p-valor < 0,01) na amostra AL/EUA. Tal resultado vai ao encontro daqueles de Maksimovic e Zechner (1991) e dá indícios de que empresas com baixa eficiência tecnológica aumentam seu endividamento como forma de compensar a perda de rentabilidade provocada pela menor eficiência. Porém, na América Latina, conquanto positivos, os coeficientes foram indistinguíveis de zero. Por fim, o Poder de Barganha dos Clientes (p-valor $<0,05)$ e dos Fornecedores $(\mathrm{p}$-valor $<0,05)$ apresentaram a relação positiva proposta por Kale e Shahrur (2007) e sugerem que as empresas aumentam o endividamento para diminuir a pressão exercida pelos clientes e fornecedores.

No tocante ao grupo de variáveis macroeconômicas, inicialmente, a relação da Alavancagem foi positiva com PIB per capita (p-valor < 0,05), o que confirmam Demirgüç-Kunt e Maksimovic (1999), e indica que, em economias maiores, as empresas podem captar maior nível de endividamento. Não se encontrou relação significativa entre Alavancagem e Crescimento do PIB, ao contrário de Jong et al. (2008), que encontraram relação positiva, e Kayo e Kimura (2011), que detectaram relação negativa. No entanto ressalta-se que suas amostras são consideravelmente mais abrangentes que a do presente estudo.

Foram encontrados indícios de que com Taxa de Inflação (p-valor < 0,05) mais alta, o endividamento corporativo é menor. Esse resultado está de acordo com a sugestão de Fan et al. (2012) de que, com a economia dando sinais de aumento de risco, as empresas se endividam menos. Por fim, a Taxa Real de Juros indicou relação negativa com o endividamento (p-valor $<0,01$ ), o que contraria as expectativas. Uma possível explicação é o fato de os gestores se anteciparem a mudanças esperadas na Taxa Real de Juros, de modo que, no mesmo período de tempo, a relação é negativa. Em testes não reportados, defasou-se a medida de Taxa Real de Juros e encontrou-se a relação negativa esperada com p-valor < 0,01 para a amostra AL/EUA, porém indistinguível de zero na América Latina.

Por sua vez, os resultados da inclusão dos fatores relacionados ao Desenvolvimento Financeiro e Qualidade das Instituições merecem destaque. Inicialmente, a inclusão do fator relacionado ao Desenvolvimento Financeiro apresentou relação positiva com a Alavancagem nos países latinoamericanos (p-valor < 0,01). Quando se incluíram as empresas norte-americanas na amostra, o coeficiente do fator inverteu de sinal e manteve $\mathrm{p}$-valor $<0,01$. Esse resultado vai ao encontro de Fan $e t$ al. (2012), cujos dados encontrados sugerem que, em economias emergentes, a relação entre o aumento na segurança dos depósitos no sistema bancário (deposit insurance) e o endividamento corporativo é positiva; ao passo que, em economias desenvolvidas, é negativa. Destaca-se que o número de observações das empresas norte-americanas corresponde a aproximadamente $58 \%$ da amostra AL/EUA, conforme se pode verificar na Tabela 3. Nesse caso, há indícios de que a inversão do sinal se deu devido ao maior Desenvolvimento Financeiro dos Estados Unidos.

$\mathrm{O}$ fator relacionado à Qualidade das Instituições apresentou sinal do coeficiente negativo e pvalor < 0,05. O sinal encontrado vai de encontro a Demirgüç-Kunt e Maksimovic (1999) e Giannetti (2003), porém está de acordo com Li et al. (2009). Resumidamente, os resultados encontrados na Tabela 4 (isto é, o sinal negativo do fator Qualidade das Instituições) podem ser explicados pelo eventual desenvolvimento desigual nos mercados, de forma que a relação negativa encontrada pode estar relacionada ao aumento do lançamento de ações no período analisado (que, devido à construção da variável em foco, deveria apresentar relação negativa com o endividamento). Ou seja, o sinal negativo do fator Qualidade das Instituições pode ter indicado seu efeito no desenvolvimento do mercado acionário. 
Para avaliar a hipótese levantada por Li et al. (2009) e capturar o efeito do mercado acionário na variável dependente em análise, incluiu-se a variável Capitalização do Mercado de Ações $\left(\mathrm{CMA}_{000 \mathrm{p}}\right)$ como medida do desenvolvimento do mercado acionário e um termo de interação com o fator Qualidade das Instituições $\left(\mathrm{QI}_{000 \mathrm{p}}\right)$. De forma simplificada, foi incluída na equação 8 o termo $\left(\alpha_{1}+\right.$ $\left.\alpha_{2} \cdot \mathrm{QI}_{000 \mathrm{p}}\right) \cdot \mathrm{CMA}_{000 \mathrm{p}}$. Baseado em Li et al. (2009), deve-se esperar sinal negativo para o coeficiente $\alpha_{1}$ e sinal negativo para $\alpha_{2}$ (o que indicaria o efeito de relação entre Qualidade Institucional e Mercado Acionário). A Tabela 5 apresenta os resultados obtidos ${ }^{(3)}$.

Tabela 5

Análise Multinível - Teste para o Efeito da Qualidade Institucional no Desenvolvimento do Mercado Acionário

\begin{tabular}{|c|c|c|c|c|}
\hline \multirow[b]{2}{*}{ Var. Independentes } & \multicolumn{2}{|c|}{ Amostra AL/EUA } & \multicolumn{2}{|c|}{ América Latina } \\
\hline & I & II & III & IV \\
\hline Variáveis binárias para anos & Sim & Sim & Sim & Sim \\
\hline Constante & $0,14 * * *$ & $0,15 * * *$ & $0,13 * *$ & $0,19 * * *$ \\
\hline \multicolumn{5}{|l|}{ Variáveis em nível de firma: } \\
\hline Tangibilidade & $0,04 * * *$ & $0,04 * * *$ & $0,07 * * *$ & $0,07 * *$ \\
\hline Lucratividade & $-0,32 * * *$ & $-0,32 * * *$ & $-0,49 * * *$ & $-0,50 * * *$ \\
\hline Carga fiscal & $-0,94 * * *$ & $-0,97 * * *$ & $-1,14 * * *$ & $-1,12 * * *$ \\
\hline Op. de Crescimento & $-0,03 * * *$ & $-0,03 * * *$ & $-0,07 * * *$ & $-0,07 * * *$ \\
\hline Tamanho & $0,02 * * *$ & $0,02 * * *$ & $0,03 * * *$ & $0,03 * * *$ \\
\hline Liquidez & $-0,07 * * *$ & $-0,07 * * *$ & $-0,04$ & $-0,06 * *$ \\
\hline ADR & 0,00 & $-0,01$ & $-0,02$ & $-0,02$ \\
\hline \multicolumn{5}{|l|}{ Variáveis Setoriais: } \\
\hline Munificência & $-0,06 * * *$ & $-0,05 * * *$ & $-0,05 * *$ & $-0,05 * *$ \\
\hline Dinamismo & $0,07 * * *$ & $0,07 * * *$ & 0,04 & 0,03 \\
\hline Concentração & $-0,00^{*}$ & $-0,00^{*}$ & 0,00 & 0,00 \\
\hline Ciclo de Vida do Setor & $-0,01$ & $-0,02$ & $-0,04$ & $-0,05$ \\
\hline Dispersão da Eficiência Tecnológica & $-0,00 * * *$ & $-0,00 * * *$ & 0,00 & 0,00 \\
\hline Dispersão da Qualidade dos Produtos & 0,02 & 0,01 & $-0,05$ & $-0,05$ \\
\hline Poder de Barganha dos Clientes & $-0,00 * * *$ & $-0,00 * * *$ & $-0,00 * * *$ & $-0,00 * * *$ \\
\hline Poder de Barganha dos Fornecedores & $0,00 * * *$ & $0,00 * * *$ & $0,00 * *$ & $0,00 * *$ \\
\hline \multicolumn{5}{|l|}{ Variáveis Macroeconômicas: } \\
\hline PIB per capita & $0,00 * * *$ & $0,00 * *$ & $-0,00 * * *$ & $-0,00 * * *$ \\
\hline Crescimento do PIB & $-0,02$ & 0,07 & 0,07 & 0,00 \\
\hline Taxa de Inflação & 0,00 & $-0,11 * *$ & $-0,20 * * *$ & $-0,18 * *$ \\
\hline Taxa Real de Juros & $0,12 * * *$ & $0,15 * * *$ & $0,11 * * *$ & $0,11 * * *$ \\
\hline Variação Cambial & $0,02 *$ & $0,02 * *$ & $-0,01$ & 0,00 \\
\hline Capitalização do Mercado de Ações & $-0,03 * * *$ & $-0,03 * * *$ & $-0,00$ & $-0,01$ \\
\hline
\end{tabular}


Tabela 5 (continuação)

\begin{tabular}{lcccc}
\cline { 2 - 5 } & \multicolumn{2}{c}{ Amostra AL/EUA } & \multicolumn{2}{c}{ América Latina } \\
\hline Fatores extraídos: & & & \\
\hline Desenvolvimento Financeiro (defasado) & & $-0,07^{* * *}$ & & $0,11^{* * *}$ \\
$\begin{array}{l}\text { Qualidade das Instituições * } \\
\text { Capitalização do mercado de ações }\end{array}$ & & $0,03^{* * *}$ & & 0,03 \\
\hline AIC & -15200 & -15300 & -3612 & -3618 \\
BIC & -14959 & -15021 & -3364 & -3357 \\
\hline
\end{tabular}

Nota. $* * *, * *$ e * indicam significância de $1 \%, 5 \%$ e $10 \%$, respectivamente.

Nota-se que, os sinais dos coeficientes das novas variáveis estão de acordo com o esperado em todos os casos e apresentam p-valor < 0,01 na amostra AL/EUA. Demirgüç-Kunt e Maksimovic (1999) sugerem que mercados de ações desenvolvidos aumentem a capacidade de diversificação por parte dos empreendedores e, assim, incentivam a substituir o financiamento via dívida de longo prazo pelo financiamento via ações. Já Jong et al. (2008) afirmam que mercado de capitais desenvolvido aumenta a disponibilidade de recursos para financiamento, o que diminui o custo de capital das empresas. Em síntese, o sinal negativo para Capitalização do Mercado de Ações, apresentado na Tabela 5, sugere que os resultados aqui levantados são consistentes com essas hipóteses.

Adicionalmente, o sinal positivo do termo de interação indica que o efeito do mercado de ações no endividamento depende da Qualidade Institucional. Percebe-se que os resultados da Tabela 5 são contrários àqueles de Demirgüç-Kunt e Maksimovic (1999), porém confirmam a hipótese de Li et al. (2009). Em suma, o presente trabalho dá indícios de que a Qualidade Institucional e o mercado acionário são, em conjunto, fatores relevantes (e relacionam-se) para a decisão de endividamento corporativo.

\section{Análise de sensibilidade}

Na penúltima etapa do presente estudo, procedeu-se a testes de sensibilidade dos resultados a fim de verificar se podem ser generalizados para a amostra e período em questão. Utilizou-se, para tanto, o procedimento de Leamer (1985), em que as estimativas dos coeficientes são refeitas, excluindo-se, alternadamente: (a) um país da amostra; (b) um ano do período; ou (c) um setor econômico. Ao todo, são estimados 36 novos coeficientes ${ }^{(4)}$. De modo geral, os novos coeficientes variam pouco em relação ao parâmetro original. Raros são os casos em que sua média difere do valor original (a maior diferença foi de apenas 0,02). Além disso, salvo para as variáveis Carga Fiscal, Crescimento Real do PIB e Taxa de Inflação, os desvios padrões dos novos coeficientes são baixos. Destaca-se que o coeficiente de Carga Fiscal apresentou sinal contrário ao esperado nas estimativas iniciais e na análise de sensibilidade, além de alto desvio padrão. Ou seja, uma medida mais refinada do benefício fiscal da dívida pode ser necessária em estudos posteriores. Observa-se, também, que a medida para Crescimento Real do PIB não apresentou coeficientes significativamente diferentes de zero de forma consistente nas estimativas originais, algo que se mantém nas análises de sensibilidade. Por fim, apesar do alto desvio padrão, majoritariamente, os novos coeficientes de Taxa de Inflação apresentaram sinal negativo e p-valor < 0,05. Esse resultado sugere que, apesar de instável, a relação entre a medida de inflação e endividamento não apresenta contradição.

\section{Testes de robustez}

O primeiro teste de robustez executado foi a reprodução dos modelos apenas com os países sulamericanos (isto é, excluíram-se as empresas americanas e mexicanas) ${ }^{(5)}$. O que se pôde perceber foi a manutenção dos resultados iniciais. Da mesma forma que anteriormente, a relação entre a Qualidade das Instituições e Alavancagem foi negativa ( $\mathrm{p}$-valor $<0,05$ ). Por sua vez, o sinal do coeficiente do Desenvolvimento Financeiro foi negativo (p-valor $<0,01$ ) - o que confirma os resultados anteriores. 
Além do mais, os coeficientes das demais variáveis não apresentaram diferenças notáveis em relação aos resultados iniciais.

Em sua última etapa, estimou-se a equação 8 com uma medida alternativa de Alavancagem. Seguiram-se os trabalhos de Booth, Aivazian, Demirgüç-Kunt e Maksimovic (2001) e Jörgensen e Terra (2003) e utilizou-se o quociente passivo dividido pelo ativo total (AL2). Sabe-se que, em geral, essa medida de Alavancagem considera todas as fontes de capital de terceiros utilizadas pela firma, inclusive o crédito comercial (trade credit). Para a América Latina, em especial, essa pode ser uma fonte relevante de capital, o que motivou a análise. Em resultados não reportados, após as novas estimativas, perceberam-se poucas variações em relação aos resultados obtidos com AL1. Ressalta-se apenas que os testes de sensibilidade de AL2 indicaram que os coeficientes estimados são sensivelmente mais instáveis. Como a maior parte dos resultados principais se manteve, serão discutidos aqui apenas os resultados controversos e/ou inconclusivos.

Inicialmente, a Liquidez da firma trocou de sinal em relação à AL1 e apresentou relação positiva e p-valor < 0,05 em 97\% dos novos coeficientes estimados. Deve-se observar, no entanto, que AL2 apresenta o passivo total (circulante + não circulante) em seu numerador, enquanto a medida de liquidez tem em seu numerador os ativos correntes. Uma vez que ambas as variáveis possuem o ativo total em seu denominador, o sinal positivo encontrado pode estar indicando que a correlação do passivo total e ativos correntes é positiva. Portanto, a interpretação desse coeficiente deve ser feita com cautela.

Destaca-se também a perda de significância dos coeficientes de Munificência (apenas 3\% apresentaram p-valor $<0,05$ ) e Dinamismo (nenhum coeficiente apresentou p-valor $<0,05$ ). Tomando em conjunto com os resultados de AL1, diferentemente de Kayo e Kimura (2011), o efeito do Dinamismo no endividamento é ambíguo. Uma possível explicação para tais resultados é o fato de que a amostra utilizada no presente estudo foi menor e mais homogênea que em Kayo e Kimura (2011). Consequentemente, a menor variação entre os setores pode ter dificultado a avaliação do efeito das variáveis desse nível no endividamento ${ }^{(6)}$.

Finalmente, ressalta-se que, quando se considera AL2, 97\% dos coeficientes de Desenvolvimento Financeiro mantêm a relação negativa e apresentam p-valor $<0,05$. Logo, a relação negativa encontrada (entre o fator e a variável dependente) independe da medida de Alavancagem utilizada. Percebe-se novamente o reflexo da inclusão das empresas americanas na amostra, na medida em que se obtém sinal do coeficiente positivo (mas insignificante) apenas com a sua exclusão. Adicionalmente, destaca-se que parcela significativa (i.e., 66\%) dos coeficientes de Qualidade das Instituições trocou de sinal em relação a AL1 e apresentou relação positiva. No entanto apenas 3\% (isto é, apenas um dos 36 novos coeficientes) apresentaram $\mathrm{p}$-valor $<0,05$, o que sugere que a troca de sinal não é significativa.

\section{Considerações Finais}

O presente estudo investigou quais são os determinantes relevantes para a Alavancagem corporativa na América Latina com ênfase no Desenvolvimento Financeiro e na Qualidade das Instituições como variáveis independentes. Para tanto, utilizou-se o Modelo Linear Hierárquico, que controla diferentes níveis de influência das variáveis explicativas. De modo geral, os resultados das variáveis em nível de firma indicam que nenhuma das hipóteses teóricas relacionadas às decisões de estrutura de capital consegue, de forma isolada, explicar as decisões de captação de recursos de terceiros, porém explicam parcialmente os resultados.

Os resultados da decomposição da variância sugerem que as variações entre as empresas e as variações ao longo do tempo são as maiores fontes de variabilidade do endividamento - o que corrobora Kayo e Kimura (2011). Juntos, nas diferentes amostras estudadas, esses níveis são fontes em torno de 85\% das variações na Alavancagem. Destaca-se, ainda, que, quando se consideram apenas as empresas brasileiras, as variações setoriais representaram, aproximadamente, $4,8 \%$ das variações na 
Alavancagem, porém representam em torno de $21 \%$ quando se analisa somente empresas dos Estados Unidos. Observou-se, também, que a inclusão das variáveis Munificência, Poder de Barganha dos Clientes e dos Fornecedores revelaram coeficientes significativos.

No que concerne ao resultado obtido pela inclusão dos fatores de Desenvolvimento Financeiro e Qualidade das Instituições, alguns pontos merecem destaque. Identificou-se, inicialmente, que, para os países latino-americanos, o fator Desenvolvimento Financeiro impacta positivamente no acesso a recursos de terceiros. Tal resultado sugere que, em economias mais voláteis, maior Desenvolvimento Financeiro auxilia no acesso das firmas aos recursos de terceiros. Além disso, o fator Qualidade das Instituições revelou relação negativa com a Alavancagem. Posteriormente, obtiveram-se indícios de que a Qualidade Institucional fortalece o desenvolvimento do mercado de ações, assim, confirmando os achados de Li et al. (2009). Por fim, não se encontrou relação de sobreposição entre Desenvolvimento Financeiro e Qualidade Institucional, uma vez que em todos os modelos os coeficientes apresentaram p-valor $<0,10$.

Finalmente, os resultados se revelaram robustos no tocante a uma série de testes de sensibilidade, o que indica que os resultados não sobrem viés de um ano, um setor ou um país da amostra. Não se pode deixar de mencionar, no entanto, que a análise conjunta de AL1 e AL2 sugere que a relação entre endividamento e algumas variáveis mostrou-se inconclusiva. A medida de Dinamismo, por exemplo, não apresentou significância na maior parte das estimativas e a variável Carga Fiscal assinalou resultados contraditórios.

\title{
Notas
}

\begin{abstract}
${ }^{1}$ As variáveis incluídas são (valor médio dos loadings entre parênteses): Liquid liabilities/GDP (0,927), deposit Money bank assets/GDP $(0,765)$, private credit by deposit Money Banks/GDP $(0,748)$, private credit by deposit Money Banks and other financial institutions/GDP $(0,722)$, bank deposits/GDP $(0,932)$, financial system deposits/GDP $(0,932)$, bank credit/bank deposits $(-0,029)$, liquid liabilities (in mil. 2000 usd) $(0,414)$, bank overhead costs/total assets $(-0,342)$, net interest margin ($0,419)$, bank concentration $(-0,223)$, bank ROA $(-0,058)$, bank ROE $(-0,110)$, bank cost-income ratio $(-0.102)$, loans from nonresident Banks (AMT outstanding)/GDP (0,483), e offshore bank deposits/domestic bank deposits $(0,086)$.

${ }^{2}$ As variáveis incluídas são (valor médio dos loadings entre parênteses): Voice and Accountability (0,883), Political Stability $(0,846)$, Government Effectiveness (0,963), Regulatory Quality (0,933), Rule of Law $(0,973)$ e Control of Corruption $(0,952)$.

${ }^{3}$ A nova variável foi medida pelo quociente entre Capitalização das firmas de capital aberto e PIB (Beck, Demirgüç-Kunt, \& Levine, 2010). Demirgüç-Kunt e Maksimovic (1999), Giannetti (2003), Jong et al. (2008) e Kayo e Kimura (2011) utilizaram a mesma variável. Nas análises da Tabela 5, excluiu-se o fator Qualidade das Instituições $\left(\mathrm{IN}_{000 \mathrm{p}}\right)$ para evitar colinearidade com o termo de interação, porém os resultados (não reportados) permanecem iguais com a sua inclusão.

${ }^{4}$ Resultados não reportados, mas disponível sob pedido aos autores.

${ }^{5}$ Resultados não reportados, mas disponível sob pedido aos autores.

${ }^{6}$ Outra possibilidade seria o fato de Kayo e Kimura (2011) terem consolidado os efeitos setoriais em apenas três variáveis ao passo que o presente estudo considerou oito. Nesse caso, o efeito do nível setorial (que é pequeno na presente amostra) teria sido diluído em um grande número de variáveis, o que dificultou a rejeição de betas iguais a zero. Para avaliar tal hipótese, em testes não reportados, procedeu-se a análise com apenas as variáveis Munificência, Dinamismo e Concentração. Os resultados apontaram relação negativa entre endividamento e Munificência ( $\mathrm{p}$-valor $<0,05$ ) e Concentração ( $\mathrm{p}$-valor $<0,10$ na análise com AL2). Porém Dinamismo apresentou relação positiva com AL1 (p-valor < 0,01) e negativa com AL2 (insignificativa). Em resumo, há indícios de que a hipótese de diluição do efeito setorial em um grande número de variáveis deve ser rejeitada e o efeito de Dinamismo no endividamento é inconclusivo na presente amostra.
\end{abstract}

\section{Referências}

Allayannis, G., \& Ofek, E. (2001). Exchange rate exposure, hedging, and the use of foreign currency derivatives. Journal of International Money and Finance, 20(2), 273-296. doi: 10.1016/S02615606(00)00050-4 
Almazan, A., \& Molina, C. A. (2005). Intra-industry capital structure dispersion. Journal of Economics \& Management Strategy, 14(2), 263-297. doi: 10.1111/j.1530-9134.2005.00042.x

Antoniou, A., Guney, Y., \& Paudyal, K. (2006). The determinants of debt maturity structure: evidence from France, Germany and the UK. European Financial Management, 12(2), 161-194. doi: $10.1111 /$ j.1354-7798.2006.00315.x

Barclay, M. J., \& Smith, C. W. (1995). The maturity structure of corporate debt. Journal of Finance, 50(2), 609-631.

Baxter, N. D. (1967). Leverage, risk of ruin and the cost of capital. The Journal of Finance, 22(3), 395403. doi: 10.1111/j.1540-6261.1967.tb02975.x

Beck, T., Demirgüç-Kunt, A., \& Levine, R. (2010). Financial institutions and markets across countries and over time: the updated financial development and structure database. World Bank Economic Review, 24(1), 77-92. doi: 10.1093/wber/lhp016

Booth, L., Aivazian, V., Demirgüç-Kunt, A., \& Maksimovic, V. (2001). Capital structure in developing countries. Journal of Finance, 56(1), 87-130. doi: 10.1111/0022-1082.00320

Céspedes, J., González, M., \& Molina C. A. (2010). Ownership and capital structure in Latin America. Journal of Business Research, 63(3), 248-254. doi: 10.1016/j.jbusres.2009.03.010

Copat, R. (2009, julho/agosto). Direcionadores-chave da estrutura de capital corporativa na América Latina. Anais do Encontro Brasileiro de Finanças, São Leopoldo, RS, Brasil, 9.

Copat, R., \& Terra, P. R. S. (2009, setembro). Estrutura de capital internacional: comparando América Latina e Estados Unidos. Anais do Encontro Nacional da Associação Nacional de PósGraduação e Pesquisa em Administração, São Paulo, SP, Brasil, 33.

Demirgüç-Kunt, A., \& Maksimovic, V. (1998). Law, finance, and firm growth. Journal of Finance, 53(6), 2107-2137.

Demirgüç-Kunt, A., \& Maksimovic, V. (1999). Institutions, financial markets, and firm debt maturity. Journal of Financial Economics, 54(3), 295-336. doi: 10.1016/S0304-405X(99)00039-2

Fama, E. F., \& French, K. R. (2002). Testing trade-off and pecking order predictions about dividends and debt. Review of Financial Studies, 15(1), 1-33. doi: 10.2139/ssrn.199431

Fan, J. P. H., Titman, S., \& Twite, G. (2012). An international comparison of capital structure and debt maturity choices. Journal of Financial and Quantitative Analysis, 47(1), 23-56. doi: $10.3386 /$ w16445

Giannetti, M. (2003). Do better institutions mitigate agency problems? Evidence from corporate finance choices. Journal of Financial and Quantitative Analysis, 38, 185-212.

Guedes, J., \& Opler, T. (1996). The determinants of the maturity of corporate debt issues. Journal of Finance, 51(1), 1809-1833. doi: 10.1111/j.1540-6261.1996.tb05227.x

Guney, Y., \& Ozkan, A. (2005). New insights on the importance of agency costs for corporate debt maturity decisions. Applied Financial Economics Letters, 1(4), 233-238. doi: 10.1080/17446540500117610

Harris, M., \& Raviv, A. (1991). The theory of capital structure. Journal of Finance, 46(1), 297-355. doi: $10.1111 / \mathrm{j} .1540-6261.1991 . t b 03753 . x$

Jensen, M. C. (1986). Agency costs of free cash flow, corporate finance and takeovers. American Economic Review, 76(2), 323-339. 
Jensen, M. C., \& Meckling, W. H. (1976). Theory of the firm: managerial behavior, agency costs and ownership structure. Journal of Financial Economics, 3(4), 305-360. doi: 10.1016/0304405X(76)90026-X

Jong, A. de, Kabir, R., \& Nguyen, T. T. (2008). Capital structure around the world: the roles of firmand country-specific determinants. Journal of Banking \& Finance, 32(9), 1954-1969. doi: 10.1016/j.jbankfin.2007.12.034

Jörgensen, J. J., \& Terra, P. R. S. (2003, junho). Determinants of capital structure in Latin America: the role of firm-specific and macroeconomic factors. Annual Meeting of Multinational Finance Society, Montreal, Quebec, Canada, 10.

Kale, J. R., \& Shahrur, H. (2007). Corporate capital structure and the characteristics of suppliers and customers. Journal of Financial Economics, 83(2), 321-365. doi: 10.1016/j.jfineco.2005.12.007

Kaufmann, D., Kraay, A., \& Mastruzzi, M. (2009). Governance matters VIII: governance indicators for 1996-2008 [Working Paper $\mathrm{n}^{\circ}$ 4978]. World Bank Policy Research. Recuperado de https://openknowledge.worldbank.org/bitstream/handle/10986/4170/WPS4978.pdf?sequence=1

Kayo, E. K., \& Kimura, H. (2011). Hierarchical determinants of capital structure. Journal of Banking \& Finance, 35(2), 358-371. doi: 10.1016/j.jbankfin.2010.08.015

Kirch, G., \& Terra, P. R. S. (2012). Determinants of corporate debt maturity in South America: do institutional quality and financial development matter? Journal of Corporate Finance, 18(4), 980993. doi: 10.1016/j.jcorpfin.2012.05.004

Knebel, E. von, Schmidt-Hebbel, K., \& Thunert, M. (2011). Chile report. Sutainable governance indicators. Recuperado de http://www.sgi-network.org/pdf/SGI11_Chile.pdf

Kraus, A., \& Litzenberger, R. H. (1973). A state-preference model of optimal financial leverage. Journal of Finance, 28(4), 911-922. doi: 10.1111/j.1540-6261.1973.tb01415.x

La Porta, R., Lopez-de-Silanes, F., Shleifer, A., \& Vishny, R. W. (1998). Law and finance. Journal of Political Economy, 106(5), 1113-1155. doi: 0022-3808/98/0606-0006\$02.50

Leamer, E. E. (1985). Sensitivity analyses would help. American Economic Review, 75(3), 308-313. doi: 10.1016/0169-2070(86)90114-7

Li, K., Yue, H., \& Zhao, L. (2009). Ownership, institutions, and capital structure: evidence from China. Journal of Comparative Economics, 37(3), 471-490. doi: 10.1016/j.jce.2009.07.001

Mackay, P., \& Phillips, G. M. (2005). How does industry affect firm financial structure? The Review of Financial Studies, 18(4), 1433-1466. doi: 10.1093/rfs/hhi032

Maksimovic, V. (1988). Capital structure in repeated oligopolies. RAND Journal of Economics, 19(3), 389-407.

Maksimovic, V., \& Zechner, J. (1991). Debt, agency costs, and industry equilibrium. The Journal of Finance, 46(5), 1619-1643. doi: 10.1111/j.1540-6261.1991.tb04637.x

Miller, M. H. (1977). Debt and taxes. Journal of Finance, 32(2), 261-275.

Miller, M. H., \& Modigliani, F. (1961). Dividend policy, growth and the valuation of shares. Journal of Business, 34(4), 411-433.

Modigliani, F., \& Miller, M. H. (1958). The cost of capital, corporation finance and the theory of investment. American Economic Review, 48(3), 261-297. 
Myers, S. C. (1977). Determinants of corporate borrowing. Journal of Financial Economics, 5(2), 147176. doi: $10.1016 / 0304-405 \mathrm{X}(77) 90015-0$

Myers, S. C. (1984). The capital structure puzzle. Journal of Finance, 39(3), 574-592. doi: $10.1111 / j .1540-6261.1984 . t b 03646 . x$

Myers, S. C., \& Majluf, N. S. (1984). Corporate financing and investment decisions when firms have information that investors do not have. Journal of Financial Economics, 13(2), 187-221. doi: $10.1016 / 0304-405 \mathrm{X}(84) 90023-0$

Ozkan, A. (2000). An empirical analysis of corporate debt maturity structure. European Financial Management, 6(2), 197-212. doi: 10.1111/1468-036X.00120

Rabe-Hesketh, S., \& Skrondal, A. (2008). A multilevel and longitudinal modeling using STATA (2a ed.). College Station: Stata Press.

Rajan, R. G., \& Zingales, L. (1995). What do we know about capital structure? Some evidence from international data. Journal of Finance, 50(5), 1421-1460. doi: 10.1111/j.15406261.1995.tb05184.x

Simerly, R. L., \& Li, M. (2000). Environmental dynamism, capital structure and performance: a theoretical integration and an empirical test. Strategic Management Journal, 21(1), 31-49. doi: 10.1002/(SICI)1097-0266(200001)21:1<31::AID-SMJ76>3.0.CO;2-T

Stohs, M. H., \& Mauer, D. C. (1996). The determinants of corporate debt maturity structure. Journal of Business, 69(3), 279-312. doi: 0021-9398/96/6903-0001

Terra, P. R. S. (2011). Determinants of corporate debt maturity in Latin America. European Business Review, 23(1), 45-70. doi: 10.1108/09555341111097982

Titman, S., \& Wessels, R. (1988). The determinants of capital structure choice. Journal of Finance, 43(1), 1-19. doi: 10.1111/j.1540-6261.1988.tb02585.x 